\title{
EDITORIAL
}

\section{Twenty-Fifth Anniversary Commentary}

At the invitation of the present editors I have prepared the following commentary as a preface to this twenty-fifth anniversary volume of the Journal of Physical Oceanography. It includes some interwoven historical perspective, an index of the growth of oceanographic literature in the last 25 years, some issues facing science journals down the road, and a tribute to the reviewers and an anonymous author.

In the summer of 1969 , Ken Spengler, then executive director of the American Meteorological Society (AMS), invited me to be founding editor of a new journal devoted to physical oceanography. The Council of the AMS had just approved adding this new journal to its publication series based on perceived future needs for papers in physical oceanography and air-sea interaction. We were well into an era of tremendous opportunity for development in both geosciences and space science that emerged from the establishment of the Office of Naval Research in 1946, the National Science Foundation in 1951, and the accelerated space program following the Soviets' launching of Sputnik in 1957. By the summer of 1969 the achievement of the first Apollo landing on the moon was fresh in our minds. But more importantly to geosciences, a new technological era for global sensing of the atmosphere and ocean had already begun. Thus, the Journal of Physical Oceanography, with a first issue scheduled for early 1971, was long overdue to supplement other existing journals in meeting the demand for an explosion in the geosciences literature.

The Journal of Physical Oceanography (JPO) was swept into being on the rising tide of submitted papers; even its first volume had a competitive 300 pages. By volume 10 in 1980 , when Bill Holland and Bruce Warren took over as coeditors, the page count exceeded 2000. The latest data show that volume 23 almost reached 3000 pages, and the cumulative number of pages of JPO since its creation has exceeded 35000 . This is just one journal-no wonder our bookshelves are bulging to the limit.

Clearly, all the geoscience journals have grown in size and diversity, and new journals have come on-line to meet the demand in special subject categories for which research and development have increased. As a more global index from which to judge growth in ocean science literature since 1969, I have selected four relevant English language periodicals including JPO. The other three are the Journal of Marine Research (JMR), Deep-Sea Research (DSR), and the Journal of Geophysical Research (JGR). In compiling numbers for the four selected periodicals, care was taken to convert all page counts to a common unit, taken as the equivalent JPO page in size and format.' Figure 1 shows the combined page counts by years from 1969 to 1993 for the four journals. It indicates a linear trend with obvious perturbations and about a ninefold increase over the 25 years. The cumulative page count for the four journals is 125000 in JPO units for the 25 -year period. JPO contributes about $28 \%$ to this total.

The growth of journal papers in ocean science and the growth in number of individuals listed in the ocean science directories go hand in hand; this is consistent with the "publish or perish syndrome." Where will it lead? Is is time for journals to consider going to compact disks for archiving of papers, with only abstracts in hard copy? Maybe this will not be necessary. The level of federal funding for science is clearly a key factor here, and it looks like the golden era of funding of basic research is over. there are clear signs that the production of doctoral-level scientist by universities has exceeded available jogs; it has affected all fields including ocean science. The impact on research and production of science papers will no doubt be a tendency for yearly volume sizes to reach a stable level, which may even be somewhat less than the present as annual production of new professionals tends toward a rate close to that of attrition.

One this is sure, the last 25 years have seen the development of new technology for monitoring the ocean, both within and on its surface. Moreover, many new and exciting subject areas and concepts in ocean science have opened and will keep the science alive even with cutbacks in research support. Looking back in time before the golden era of funding that started in the 1950s, I note that Henry Stommel's landmark paper (Stommel 1948) about westward intensification of ocean circulation was apparently the result of unsponsored (but clearly inspired) research.

This issue of the journal departs from normal policy in that two of its contributions address historical aspects of ocean science. The first is a translation of a paper written in 1725 about the motions of seawater by a member of the French Royal Academy of Science. In the science time line, this paper appeared less than four decades after Newton's Principia Mathematica and

\footnotetext{
${ }^{1}$ The factors employed for conversion from actual page counts for JMR and DSR to JPO equivalents are 0.48 and 0.82 , respectively; for JGR, the conversion factors ar 0.77 prior to 1974 , and 1.13 for 1974 and thereafter.
} 


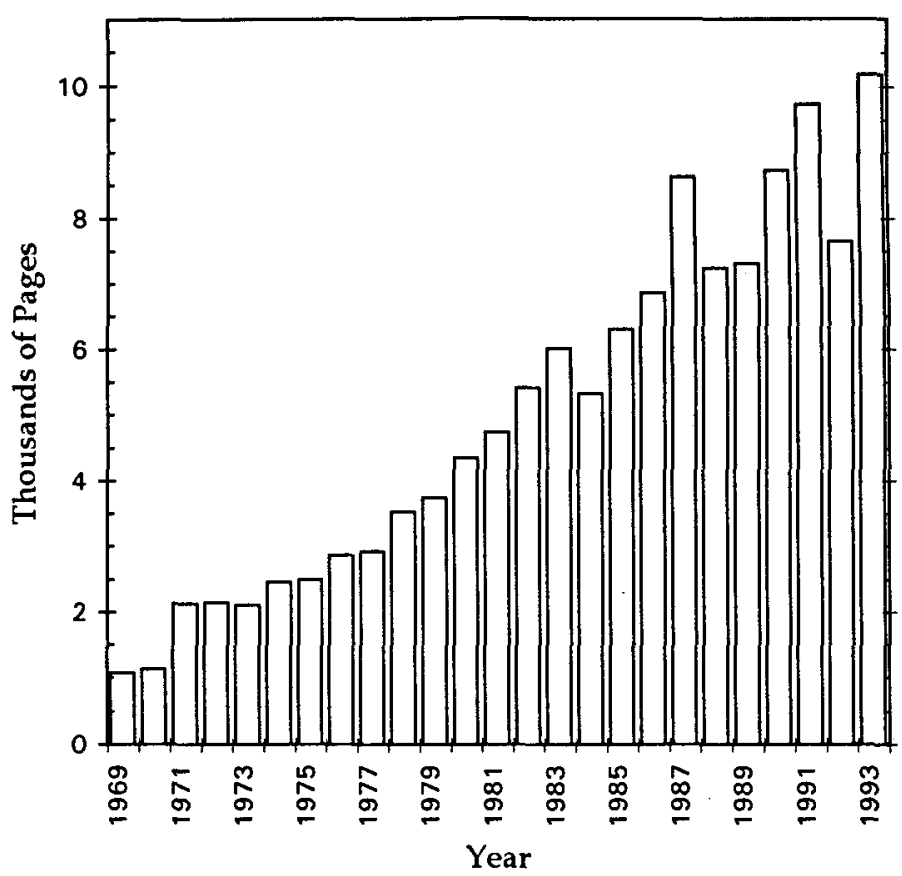

FIG. 1. Combined page count of ocean science articles by years in four representative journals in units of equivalent JPO pages.

about three decades before Benjamin Franklin's published chart of an ocean current. One of its messages is an appeal for a coordinated observation program - and a sponsor - to understand the currents in the Mediterranean Sea. The second contribution is a retrospective narrative by R. W. Schmitt who presents a previously untold story about the nineteenth century salt finger experiments by Jevons and later by Rayleigh. The fascinating part of the story addresses their motivation and why neither Jevons nor Rayleigh discovered the concept of double diffusion in the explanation of salt fingers. It was left to Melvin Stern to make this breakthrough in 1960.

Any reputation JPO has received during its relatively short life is, for the most part, attributable to the conscientiousness of the vast majority of our reviewers who have monitored the quality of the papers we have had the good fortune to publish. Many reviewers have gone well beyond that expected of them. I recall one referee who took it upon himself to rewrite a paper submitted from some Russian authors because he felt that the presentation as submitted did not do justice to the importance of the technical contribution. A present editor recalls receiving from a reviewer some very constructive comments that far exceeded the length of the submitted note. The AMS has for many years honored certain reviewers of its journals who, in the opinion of the journal editors, have consistently provided outstanding reviews.

I will close with a story stemming from the spinup phase of the new journal. In the selection of the board of associate editors, the aim was to have individuals who were recognized leaders in particular aspects of physical oceanography. The positive response from most of those I contacted was encouraging, and the AMS owes him a debt of gratitude for their willingness to help launch the journal. One individual, whom I particularly wanted, chose not to serve based on his belief that there was no real need at that time for a special journal devoted to physical oceanography. My respect for this individual's judgment gave me reason for concern. However, as the record now clearly shows, there has indeed been an explosion in oceanography. The growth has occurred in quantity and in topical diversity, and the Journal of Physical Oceanography has shared the burden of dealing with the volume of papers. Some measure of the success of any journal lies in its growth in terms of numbers of papers, but a better measure is in terms of diversity and quality of its articles and in the reputation of its authors. It is to the credit of the Journal of Physical Oceanography and the editors to whom I passed the torch in 1980 that one of its most prolific and respected authors over the last 25 years is the individual who questioned the rationale for its creation.

Robert $O$. Reid Founding Editor

\section{REFERENCES}

Stommel, H., 1948: The western intensification of wind-driven ocean currents. Trans. Amer. Geophys. Union, 29, 202-206. 